\title{
Fatores críticos no comportamento do gestor público responsável por compras sustentáveis: diferenças entre consumo individual e organizacional
}

\author{
Hugo Leonnardo Gomides do Couto \\ Universidade Federal de Goiás (UFG) \\ Cristiano Coelho \\ Pontifícia Universidade Católica de Goiás (PUCGoiás)
}

\begin{abstract}
O presente artigo investiga o comportamento de gestores públicos, identificando os fatores críticos que determinam o processo decisório de compra sustentável, seja no contexto de compras individuais (ou domésticas) ou no contexto de compras organizacionais (nesse caso, refere-se às compras públicas sustentáveis, conceito recentemente inserido na legislação brasileira). Em seguida à aplicação de questionários a um grupo de gestores públicos encarregados da elaboração de editais e condução de certames licitatórios, foram realizadas inferências estatísticas que determinaram as similitudes entre os dois contextos. A partir dos resultados, observou-se diferenças relacionadas com o contexto de compra envolvido, em especial naquelas que envolvem preço, determinações da legislação e tempo gasto nas especificações dos produtos a serem adquiridos. Chamam atenção, ademais, o fato de que alguns padrões pró-ambientais se mostram bem estabelecidos, evidenciado o resultado de campanhas desenvolvidas no âmbito da instituição.
\end{abstract}

Palavras-chave: comportamento do consumidor; compras públicas sustentáveis; licitações; gestor público.

Factores críticos en el comportamiento de los gestores públicos responsables de la compra sostenible: diferencias entre el consumo individual y organizacional

En este trabajo se investiga el comportamiento de los gerentes públicos, en la búsqueda de la identificación de los factores críticos que determinan el proceso de decisión de compra sostenible, ya sea en el contexto de las compras individuales (o domesticas) o en el contexto de la compra de la organización (en este caso, se refiere a la contratación pública sostenible, concepto recientemente introducido en la legislación brasileña). En seguida a la aplicación de cuestionarios a un grupo de gerentes públicos responsables de la preparación de los avisos y la realización de licitación, se

DOI: http://dx.doi.org/10.1590/0034-7612113443

(c)) BY-NC

Artigo recebido em 14 mar. 2013 e aceito em 19 set. 2014. 
realizaron inferencias estadísticas que determinaron las similitudes entre los comportamientos de consumo en los dos contextos. De los resultados, se encontraron diferencias relacionadas a los respectivos contextos, en especial las que incluye a los precios, las determinaciones de la ley y el tiempo empleado en las especificaciones de los productos. Llama la atención, por otra parte, el hecho de que algunas pautas de comportamientos pro-ambientales están bien establecidas, muestran el resultado de campañas desarrolladas en la institución.

Palabras clave: comportamiento de los consumidores; compras públicas sostenibles; licitación; gerente público.

Critical factors in the behavior of public managers responsible for sustainable procurement: differences between organizational and individual consumption

This paper investigates public manager behavior, in order to identify the critical factors that undergo the decision-making of a sustainable consumption, both in individual (or housing) procurement and organizational contexts of consumer behavior (in this case, it is regarded the sustainable public procurement, concept that was inserted in the Brazilian legislation recently). After questionnaires sent to a group of public managers enrolled in the elaboration of bidding documents and its conduction, there were made statistical inferences to determine the similarities between the two contexts. From the results, it was observed some differences related to the consumer behavior context, especially those involving price, legislation and time spending to specify the products to be purchased. Moreover, it was noted that some environmental friendly standards are well established, as result of campaigns developed inside the institution.

KEYWORDs: consumer behavior; sustainable public procurement; bidding processes; public manager.

\section{Introdução}

As compras governamentais, no Brasil, movimentam recursos estimados em 10 a $15 \%$ do PIB (Biderman et al., 2006; Silva e Barki, 2012), e, por tal motivo, mobilizam importantes setores da economia que se ajustam às demandas previstas nos editais de licitação, a fim de que se sagrem vencedoras de tais certames e estejam aptas a contratar com a administração pública. Desse modo, é enorme a responsabilidade do gestor público pela definição das regras e do objeto da disputa, a fim de assegurar a livre-concorrência entre os licitantes e de adquirir o melhor produto ou serviço pelo menor preço.

Adicionalmente, os cidadãos têm intensificado sua demanda por administrações que se posicionem em prol da sustentabilidade de suas ações e programas. E, considerando-se o vulto de recursos públicos envolvidos nas compras governamentais, vislumbrou-se a possibilidade de utilizar as licitações como instrumento de política pública ambiental. Especificamente, na Cúpula Mundial sobre Desenvolvimento Sustentável de Joanesburgo, em 2002, surgiu o conceito de "compras verdes" que se traduz em "promover políticas de contratação pública que favoreçam o desenvolvimento e a difusão de mercadorias e serviços favoráveis ao meio ambiente" (UN, 2002). 
A adoção de critérios de sustentabilidade nas contratações governamentais, em nível federal, foi autorizada pela Instrução Normativa SLTI/MPOG no 1 , de 19 de janeiro de 2010, a qual estabeleceu as diretrizes para a atuação do gestor público. Entretanto, a responsabilidade pela escolha de determinado bem, serviço ou obra continuou a cargo do gestor público, que atua de forma discricionária e, muitas vezes, não dispõe de ferramentas objetivas suficientes para poder valorar os ganhos ou danos ambientais de suas escolhas e, por conseguinte, para conduzir a implementação da política pública. Tal política vem sendo aperfeiçoada e integrada a outras ligadas à sustentabilidade na administração. De tal processo, foi editado o Decreto $\mathrm{n}^{\mathrm{o}}$ 7.746/2012 que trouxe como marcos para a administração pública federal: a previsão expressa da possibilidade de adoção de critérios de sustentabilidade nas contratações; a criação da Comissão Interministerial de Sustentabilidade na Administração Pública (Cisap), com a função precípua de propor a implementação de critérios, práticas e ações de logística sustentável; e a obrigatoriedade da elaboração e implementação de Planos de Gestão de Logística Sustentável (cujo detalhamento encontra-se na Instrução Normativa SLTI/MPOG no 10/2012). Dessa forma, a política pública de compras sustentáveis passou a integrar um conjunto de políticas ligadas à sustentabilidade, buscando internalizar o conceito de logística sustentável na realidade das administrações públicas.

Vários órgãos federais passaram, então, a estabelecer as diretrizes para as compras sustentáveis em seus departamentos de compras. O IBGE, órgão escolhido para esta investigação, por exemplo, estabeleceu critérios mínimos para a implementação de tal política pública, por meio da Ordem de Serviço no 05/2010, editada por sua Coordenação de Recursos Materiais, que possui a responsabilidade de normatizar os procedimentos atinentes à área. Recentemente, foi elaborado um Catálogo de Materiais Sustentáveis, que engloba uma extensa lista com sugestões de especificações para materiais de consumo usualmente adquiridos. Ademais, com fulcro nas determinações da IN SLTI/MPOG no 10/2012, o IBGE também apresentou seu Plano de Logística Sustentável (PLS).

Cumpre mencionar que, quando o gestor público define os critérios e especificações dos bens e serviços a serem adquiridos em uma compra, sua atuação é a de um consumidor. Entretanto, nesse caso, este não atua como consumidor individual, pois adquire bens e serviços que serão consumidos por outros indivíduos da organização ou pelo público em geral, sendo denominado consumidor (comprador) organizacional (Solomon, 2002). Ademais, a compra organizacional possui um processo decisório distinto por envolver, em alguns casos, um grande número de indivíduos, que constituem uma unidade de compra. Também o comprador organizacional, considerando-se o vulto das aquisições que faz, é alvo da atenção comercial, de tal modo que existe legislação específica e esquemas de auditoria, com a finalidade de manter e acentuar a conduta ética de tais agentes.

Nesse sentido, o presente artigo visa investigar o comportamento de tais gestores públicos e identificar os fatores críticos que determinam o processo decisório de compra sustentável, seja no contexto de compras individuais (ou domésticas) ou no contexto de compras organizacionais (ou compras públicas). 


\section{Revisão bibliográfica}

Brodhag (2010) alerta que estamos em um novo paradigma para as políticas públicas ambientais, pois "historicamente, as regulações de natureza ambiental têm sido focadas em atividades produtivas e industriais. A presente pressão sobre os consumidores é a resposta a um processo de transição: o consumidor é considerado um elo que produz 'sinais ao mercado' que influenciam o suprimento".

Daí se compreende a relevância do papel do consumidor no desenvolvimento dessas novas políticas públicas, voltadas para a esfera do consumo. Isso porque, sempre que alguém toma uma decisão sobre comprar (ou não) um produto ou serviço, tal conduta contribui para que se estabeleça um padrão de consumo mais ou menos sustentável (Young et al., 2010).

Nessa vertente, estão as compras públicas sustentáveis, que buscam capturar um objetivo dual: melhorar a qualidade do meio ambiente disponível a seus cidadãos, enquanto provê ao mercado uma clara indicação do que os consumidores e produtores podem almejar (Ocde, 2000).

Quando tratamos de consumidores individuais, os fatores que influenciam sua decisão de compra já são conhecidos. De acordo com Sener e Hazer (2008) e Wheale e Hinton (2007), estes podem ser a seguir relacionados: força da marca, cultura, características demográficas, recursos financeiros, hábitos, ausência de informação, estilo de vida, personalidade ou fatores éticos. Além desses fatores disposicionais, modelos que focam nos fatores situacionais têm ainda enfatizado o papel determinante do contexto imediato e das consequências passadas das decisões de consumo (Foxall, 1990, 2005, 2010; Foxall et al., 2006). Mais especificamente, Foxall e seus colaboradores têm mostrado, a partir do modelo na perspectiva comportamental (BPM - do inglês, Behavioral Perspective Model), o poder de consequências utilitárias (derivadas do uso dos produtos e/ou serviços) e consequências informativas (o feedback social derivado do consumo) sobre o comportamento do consumidor, à luz da história de aprendizagem e do cenário de consumo imediato (Oliveira-Castro e Foxall, 2005). A representação esquemática do BPM encontra-se na figura 1.

Tal modelo analisa o comportamento do consumidor a partir da tríplice contingência: antecedente, resposta e consequente, localizando o comportamento do consumidor na intersecção do cenário de consumo (espaço) com a história de aprendizagem (Pohl et al., 2006).

O cenário de consumo consiste dos estímulos discriminativos que sinalizam as consequências reforçadoras e punitivas para os diferentes comportamentos de consumidor (Foxall et al., 2011). Esses estímulos podem ser físicos (como o ponto de venda/prestação de serviços), sociais (outros consumidores presentes), regulatórios (regras próprias ou providas por terceiros, como no caso da legislação), temporais (horário de disponibilidade do local de consumo, eventos sazonais) (Foxall, 2005). Tais cenários podem variar de relativamente abertos a relativamente fechados, diferenciando-se em função do nível de possibilidades de comportamento reforçado que diferentes aberturas de cenários oferecem ao consumidor. 
Figura 1

Representação esquemática do modelo na perspectiva comportamental

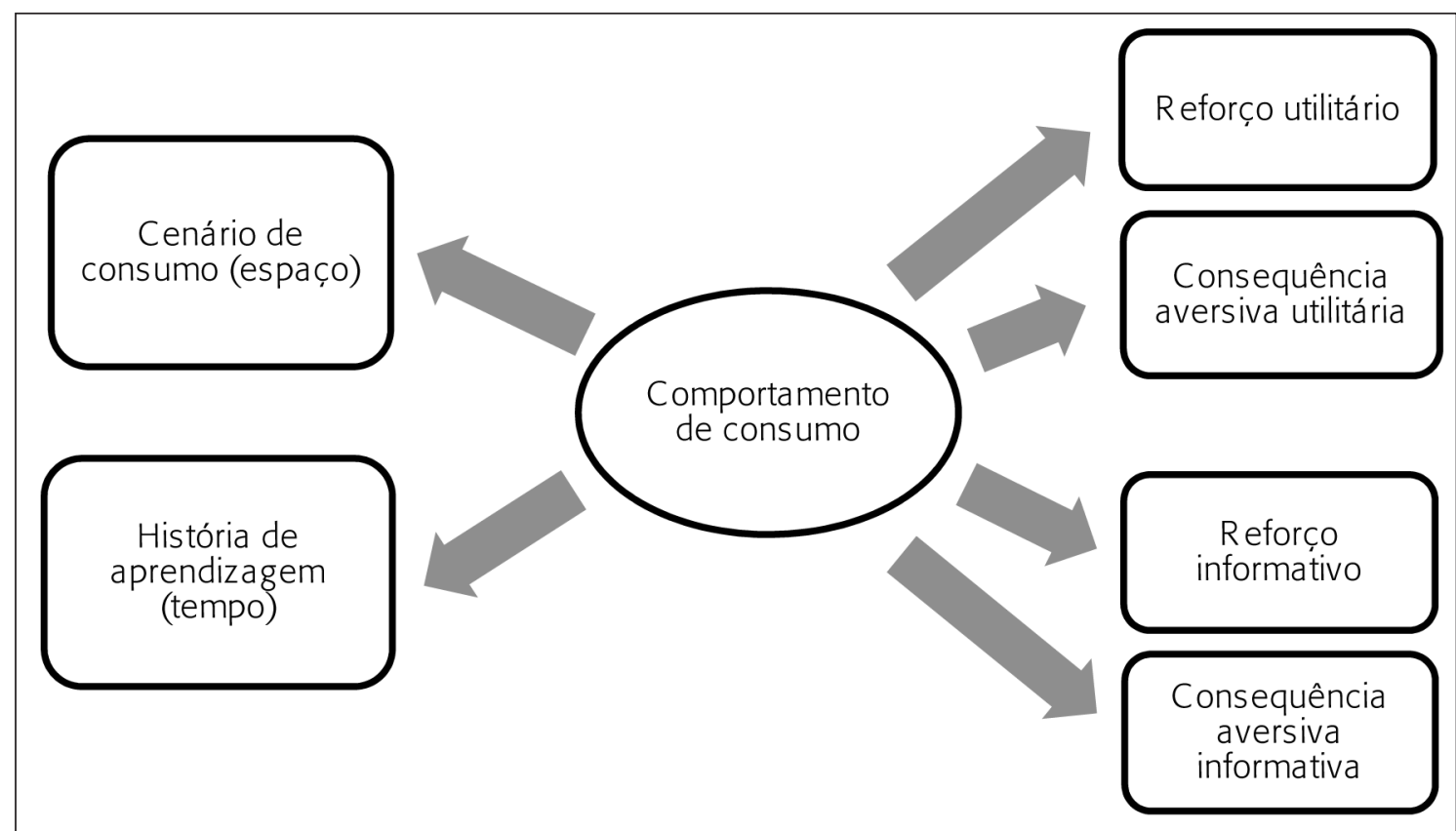

Fonte: Adaptada de Foxall (2010).

Imagine um indivíduo (que ocupa a função de gestor de compras em uma instituição pública) encarregado da compra de resmas de papel A-4. Ao adquirir tal produto para consumo doméstico, basta dirigir-se a uma das diversas papelarias da cidade e comprar o produto que melhor lhe convenha, considerando-se seus recursos financeiros, a marca que reconhece como de qualidade etc. Por sua vez, ao atuar como um comprador organizacional, o cenário de consumo é mais fechado, pois o indivíduo está submetido a uma série de restrições de comportamento: vedação à preferência por marcas; proibição do uso de certificações voluntárias (selo FSC), dentre outras. Os cenários diferentes podem, assim, tornar mais prováveis comportamentos diferentes.

O outro elemento, a história de aprendizagem (ao longo do tempo) refere-se às experiências similares e relacionadas às quais o consumidor já havia se deparado antes de encontrar a situação de compra atual e as consequências passadas de seu comportamento naquelas situações (Foxall et al., 2006). A intersecção entre a história de aprendizagem e o cenário do consumo coloca o consumidor em uma situação na qual os eventos reforçadores utilitários e informativos são sinalizados.

Nesse sentido, Green e colaboradores (2000) asseveram que, apesar do maior número de pesquisas envolvendo o comportamento do consumidor individual, muitos dos temas relevantes emergem de análises em nível organizacional, que ainda carecem de estudos que avaliem de maneira sistemática como as diferentes variáveis presentes nestes cenários in- 
fluenciam diferentemente os padrões de consumo. Paralelamente, pode-se perguntar até que ponto as próprias regras que os indivíduos têm como consumidores e que foram estabelecidas ao longo de sua história de aprendizagem regulam, mesmo que parcialmente, suas compras no contexto organizacional.

Cabe frisar que, no presente artigo, segue-se o entendimento de Wilson (2000), que critica o dualismo entre consumidores individuais e consumidores organizacionais, fundado na aparente concepção de que os consumidores domésticos compram como indivíduos livres, enquanto as organizações compram como grupos racionais. De acordo com esse autor, tais concepções podem estar equivocadas, pois os indivíduos que são responsáveis pelas compras organizacionais têm seus próprios hábitos, crenças e atitudes, que interferem nesse processo.

Há vasta literatura acerca do comportamento de consumidores individuais, que investiga os fatores que influenciam o processo decisório da compra (Young et al., 2010) ou o modo mais adequado de se realizar efetivas mudanças de comportamento em prol de padrões de consumo mais sustentáveis (Dobson, 2007). Outros estudos (Lane e Potter, 2007; Pelsmacker et al., 2005) dedicam-se até mesmo a compreender as diferenças entre as aquisições de produtos com baixo (café, papel etc.) ou alto valor agregado (veículos, eletrodomésticos etc.).

No entanto, as variáveis relacionadas com o comportamento de consumidores organizacionais são ainda pouco exploradas. De fato, os estudos estão frequentemente associados a empresas do setor privado, analisando a influência da confiança nos fornecedores (Gao et al., 2005) ou mesmo o comportamento do profissionais contratados para prestar os serviços de aquisições de uma organização (Jaakkola, 2007).

Estudos relacionados com o comportamento de consumidores organizacionais de entidades públicas (aqueles responsáveis por processos licitatórios) são ainda incipientes, ficando restritos a investigações sobre a corrupção de tais agentes (Ntayi et al., 2013).

Batista e Maldonado (2008) discutiram o papel do comprador público nas aquisições de bens e serviços, traçando uma análise da função administrativa de tal comprador na gestão de suprimentos, atrelada às exigências do modelo gerencial. Porém, sua análise não envolveu os aspectos ligados ao comportamento do consumidor. Tal lacuna pretende ser preenchida pela presente investigação. Até mesmo porque a compreensão dos fatores que influenciam o comportamento do gestor público na realização de uma compra sustentável é imprescindível para que se possa interferir no curso dessa política pública, a fim de que a mesma se efetive.

Outrossim, embora as compras públicas sustentáveis sejam matéria ainda incipiente em pesquisas, cabe destacar a importante investigação trazida por Silva e Barki (2012), que avaliou a experiência prática do Jardim Botânico do Rio de Janeiro (JBRJ) na realização de compras compartilhadas, trazendo ganhos de escala e traduzindo-se como instrumento de efetividade para a implementação da política pública.

\section{Metodologia}

Nesta seção, serão apresentados, resumidamente, os métodos de pesquisa utilizados na coleta e na análise dos dados. Foram utilizados questionários para coletar dados referentes aos 
fatores críticos que influenciam o comportamento do gestor público em face das questões ambientais, ligadas aos quatro estágios típicos do consumo, quais sejam: pré-compra, compra, uso e descarte.

Neste trabalho, utilizou-se uma amostra não probabilística de conveniência, constituída pelos servidores do IBGE lotados em suas 27 unidades estaduais (que correspondem às 27 unidades da federação) que ocupam funções de natureza gerencial no setor encarregado a realizar as compras governamentais ou que tenham sido designados como pregoeiros. Para identificar os gerentes ou supervisores de cada unidade, foi consultado o Portal da Transparência do Governo Federal. Já os pregoeiros designados foram encontrados por meio de busca às atas das cinco últimas sessões públicas de pregões eletrônicos, disponíveis no Portal de Compras do Governo Federal (Comprasnet).

No IBGE, as compras governamentais cabem às Gerências ou Supervisões de Recursos Materiais. Em algumas unidades estaduais, entretanto, tal atribuição compete à Supervisão Administrativa, a qual engloba as áreas de recursos materiais, recursos humanos e orçamento e finanças numa única estrutura. O pregoeiro, por sua vez, é o servidor designado pela autoridade competente para conduzir as licitações realizadas na modalidade pregão, instituída pela Lei no 10.520/2002. Essa modalidade, por se destinar à aquisição de bens e serviços comuns, é adotada quase na totalidade das aquisições realizadas nas unidades estaduais. O IBGE foi escolhido como órgão público a ser investigado justamente pela familiaridade dos pesquisadores com sua estrutura interna.

Cabe aqui justificar a escolha realizada, pois não foram incluídos na amostra os servidores lotados na sede administrativa do IBGE (situada no estado do Rio de Janeiro). De fato, nas unidades estaduais do IBGE, a estrutura administrativa é significativamente simples, de tal modo que a decisão quanto às compras realizadas é influenciada por poucos indivíduos, cabendo, em geral, a um único servidor a elaboração dos editais e a condução dos certames licitatórios. Esse cenário facilita a investigação aqui pretendida, pois pode-se traçar um paralelo do comportamento de um mesmo indivíduo em diferentes contextos de compra (individual e organizacional). Na sede administrativa, por sua vez, os processos de aquisições são subdivididos em várias tarefas menores, cabendo a cada servidor apenas a consecução de parte do trabalho, carecendo-lhe a visão do todo e, também, reduzindo a capacidade de influenciar o resultado. Por óbvio, as análises a serem trazidas ao longo do presente artigo restringem-se ao âmbito do IBGE, não podendo extrapolar-se para toda a administração pública, apesar de trazerem indicativos relevantes para serem comparados em investigações futuras.

A construção do questionário buscou recolher informações divididas em três partes, a saber: demográficas, funcionais (profissionais) e comportamentais. A parte I englobou as seguintes variáveis demográficas: sexo, idade, renda per capita, escolaridade e conhecimento da temática ambiental. A parte 2 , por sua vez, procurou conhecer: tempo de serviço público e no IBGE, cargo ocupado, função de natureza gerencial ocupada, participação em eventos de capacitação e conhecimento sobre compras sustentáveis.

Já a parte III apresentou aos servidores 50 afirmações, divididas em dois módulos com 25 questões cada, que versavam sobre o comportamento do indivíduo perante diversas si- 
tuações ligadas aos quatros estágios típicos do consumo. Um módulo continha afirmações (que expressam determinado comportamento) relacionadas com o contexto de compras individuais e o outro ao contexto de compras organizacionais. Ademais, cada uma das 25 afirmações de um módulo possuía uma afirmação correlata no outro módulo, diferenciando-se tão somente pelo contexto específico do tipo de compra: individual ou organizacional. Tais afirmações, no contexto de compras individuais, foram construídas com base nas seguintes referências: Sammer e Wüstenhagen (2006), McDonald e Oates (2005) e Arrais (2009). Ao servidor caberia informar com qual frequência (nunca, minoria das vezes, metade das vezes, maioria das vezes, sempre) realizava tal comportamento. Dessa forma, pode-se investigar o comportamento de um mesmo indivíduo em dois contextos distintos (compras individuais ou compras organizacionais).

A fim de se avaliar possíveis efeitos de ordem na resposta às questões, a amostra foi dividida aleatoriamente em duas, de mesmo tamanho. Para uma delas foi direcionado o questionário Tipo I, no qual as afirmações relativas ao contexto individual precediam as do contexto organizacional. Para a outra foi remetido o questionário Tipo II, com a ordem de contextos invertida: primeiro as questões sobre compras organizacionais, seguidas das questões sobre compras individuais. O possível efeito de ordem foi avaliado por meio do Teste de MannWhitney, utilizando-se o pacote estatístico do BioEstat ${ }^{\circledR}$ 5.3.

O questionário, elaborado em meio eletrônico utilizando a plataforma Google Drive ${ }_{\text {, }}$ foi remetido, por correio eletrônico, a 38 servidores, tendo-se obtido 15 respostas, o que corresponde a um índice de resposta de 39,5\%. Cabe mencionar que o questionário Tipo I obteve oito respostas e o questionário Tipo II obteve sete respostas.

Em seguida, buscou-se avaliar possíveis discrepâncias do comportamento do indivíduo quando submetido a diferentes contextos de compra (individual ou organizacional). Para tanto, comparou-se as respostas dadas em face das 25 afirmações semelhantes contidas nos dois módulos, relativos à parte III. Nesse caso, como as amostras são relacionadas, aplicou-se o Teste de Wilcoxon, com nível de decisão $\beta$ igual a 0,05, utilizando-se o pacote estatístico do BioEstat ${ }^{\circledR}$ 5.3.

Da análise estatística das respostas apresentadas pelos dois subgrupos amostrais pretende-se inferir quais são os fatores que influenciam o comportamento de consumidor em cada um dos contextos em que estão inseridos tais gestores públicos (individual e organizacional) buscando evidenciar particularidades de cada contexto.

\section{Resultados e discussões}

\subsection{Análise descritiva}

Inicialmente, em relação aos dados obtidos, foi realizada uma análise descritiva, em especial no que diz respeito às variáveis das partes I (demográficas) e II (profissionais). As variáveis da parte III (comportamentais), por sua vez, foram objeto de testes de inferência estatística. 
Na tabela 1 apresenta-se o perfil demográfico e profissional dos entrevistados, segundo as questões dos grupos I e II.

\section{Tabela 1}

\section{Perfil demográfico e profissional dos entrevistados}

\begin{tabular}{|c|c|c|c|}
\hline \multicolumn{2}{|l|}{ Parte I (variáveis demográficas) } & \multicolumn{2}{|l|}{ Parte II (variáveis profissionais) } \\
\hline Variável & Percentual & Variável & Percentual \\
\hline $\begin{array}{l}\text { Sexo } \\
\text { Masculino } \\
\text { Feminino }\end{array}$ & $\begin{array}{l}87 \% \\
13 \%\end{array}$ & $\begin{array}{l}\text { Ano de ingresso no IBGE } \\
\text { Até } 1988 \\
2000-12\end{array}$ & $\begin{array}{l}33 \% \\
67 \%\end{array}$ \\
\hline $\begin{array}{l}\text { Faixa etária } \\
\text { 30-39 anos } \\
\text { 40-49 anos } \\
\text { 50-59 anos } \\
60 \text { anos ou mais }\end{array}$ & $\begin{array}{r}40 \% \\
27 \% \\
27 \% \\
6 \%\end{array}$ & $\begin{array}{l}\text { Cargo ocupado } \\
\text { Tecnologista ou Analista } \\
\text { Técnico }\end{array}$ & $\begin{array}{l}73 \% \\
27 \%\end{array}$ \\
\hline \multirow{2}{*}{$\begin{array}{l}\text { Renda do grupo familiar } \\
R \$ 4.000 \text { a } R \$ 8.000 \\
R \$ 8.000 \text { a } R \$ 12.000 \\
R \$ 12.000 \text { a } R \$ 16.000 \\
\text { Acima de } R \$ 16.000\end{array}$} & $\begin{array}{l}34 \% \\
33 \%\end{array}$ & $\begin{array}{l}\text { Ocupa função gerencial? } \\
\text { Não } \\
\text { Supervisão } \\
\text { Gerência }\end{array}$ & $\begin{array}{l}33 \% \\
47 \% \\
20 \%\end{array}$ \\
\hline & $13 \%$ & $\begin{array}{l}\text { É pregoeiro? } \\
\text { Não } \\
\text { Sim }\end{array}$ & $\begin{array}{l}40 \% \\
60 \%\end{array}$ \\
\hline $\begin{array}{l}\text { Escolaridade } \\
\text { Médio } \\
\text { Graduação } \\
\text { Pós-Graduação (lato sensu) } \\
\text { Mestrado }\end{array}$ & $\begin{array}{r}7 \% \\
27 \% \\
33 \% \\
33 \%\end{array}$ & $\begin{array}{l}\text { Participou de quantos eventos de capacitação } \\
\text { em licitações? } \\
\text { Nenhum } \\
\text { Até } 5 \text { eventos } \\
6 \text { - } 10 \text { eventos } \\
\text { Acima de } 10 \text { eventos }\end{array}$ & $\begin{array}{r}13 \% \\
47 \% \\
27 \% \\
13 \%\end{array}$ \\
\hline $\begin{array}{l}\text { Cursou disciplinas ligadas à temática } \\
\text { ambiental? } \\
\text { Não } \\
\text { Sim (até } 40 \text { horas) } \\
\text { Sim (mais de } 40 \text { horas) }\end{array}$ & $\begin{array}{l}53 \% \\
27 \% \\
20 \%\end{array}$ & $\begin{array}{l}\text { Participou de algum evento sobre compras } \\
\text { sustentáveis? } \\
\text { Não } \\
\text { Sim }\end{array}$ & $\begin{array}{l}67 \% \\
33 \%\end{array}$ \\
\hline
\end{tabular}

Fonte: Dados da pesquisa.

Em relação aos resultados trazidos pela tabela 1, alguns pontos merecem destaque e/ ou aprofundamento da análise.

Primeiramente, deve-se ter em mente que os entrevistados apresentam elevada escolaridade, uma vez que $66 \%$ dos servidores possuem pós-graduação (lato sensu) ou mestrado. Isso evidencia duas realidades: 1 ) que os quadros que ingressaram no serviço público por concurso (67\% dos servidores entrevistados ingressaram no IBGE após a exigência constitucional de realização de concursos públicos) são compostos por servidores especializados; 2) que há indícios de que a qualificação tem sido estimulada, uma vez que o plano de cargos e carreiras 
do IBGE (instituído pela Lei no $11.355 / 2006$ ) gratifica seus servidores, em especial aqueles de nível superior, com base na titulação alcançada.

Em segundo lugar, deve-se atentar para o fato de que $73 \%$ dos entrevistados ocupam os cargos de tecnologista ou de analista, que são cargos de nível superior e, por conseguinte, que apresentam as maiores remunerações da instituição. Isso sinaliza que a instituição vem destinando seus servidores mais capacitados (em tese) para atuar em suas compras governamentais, possivelmente em virtude da natureza complexa da atividade.

Outro aspecto a ser considerado reside no fato de que, apesar da elevada escolaridade dos servidores entrevistados, vê-se que os mesmos receberam pouca capacitação para atuar em relação às questões ambientais. Por exemplo, evidencia-se que 53\% dos servidores nunca cursaram qualquer disciplina ligada à temática ambiental durante sua formação escolar/acadêmica. Além disso, especificamente sobre o tema investigado neste artigo, apesar de $87 \%$ dos respondentes terem realizado treinamentos sobre licitações, 67\% dos servidores entrevistados afirmaram não ter recebido qualquer espécie de treinamento ou capacitação relativa ao tema das compras públicas sustentáveis. Este mostra que, apesar de a legislação prever a adoção de critérios de sustentabilidade (veja instrução normativa SLTI/MPOG no 01/2010), não têm sido utilizados instrumentos que forneçam uma preparação específica direcionada aos requisitos necessários para a adoção dos critérios estabelecidos.

\subsection{Efeito de ordem das questões}

Passa-se agora à análise dos dados referentes às questões da parte III, que tratam do comportamento de consumo do gestor público responsável por compras sustentáveis, nos contextos individual e organizacional. Para tanto, inicialmente, cabe investigar a consistência dos resultados obtidos. Fez-se isso avaliando um possível efeito de ordem das questões no formulário remetido aos entrevistados, como já mencionado. Da aplicação do Teste de Mann-Whitney para as respostas dadas a cada questão em um mesmo contexto entre os participantes que responderam inicialmente sobre compras individuais e os que responderam inicialmente sobre compras organizacionais, com nível de decisão $\alpha$ igual a 0,05, obteve-se os resultados explicitados na tabela 2.

Por meio dos resultados trazidos pela tabela 2, pode-se concluir que 23 das 25 afirmações remetidas aos entrevistados foram estatisticamente semelhantes. As duas afirmações sobre o consumo individual para as quais as respostas diferiram entre os dois tipos foram a I12 e I19. Em relação à afirmação "I12. Prefiro desligar os aparelhos a deixá-los em stand-by (modo espera) quando não os utilizo.", as respostas dos entrevistados que receberam o questionário Tipo I (contexto individual anterior ao organizacional) possuem mediana igual a 2. Por sua vez, a mediana das respostas daqueles que responderam à afirmação 112 após terem respondido afirmação semelhante (mas num contexto organizacional — questionário Tipo II) foi igual a 5 . 
Tabela 2

\section{Análise da consistência das respostas às afirmações da parte III para o contexto de compras individuais entre os respondentes que iniciaram por compra individual e os respondentes que iniciaram por compra organizacional, a partir da aplicação do Teste de Mann-Whitney, com nível de decisão $\alpha<=0,05$}

\begin{tabular}{|c|c|}
\hline Afirmações sobre compras individuais & P (bilateral) \\
\hline 11. Utilizo os versos das páginas & 0,6434 \\
\hline 12. Adquiro os produtos de menor preço & 0,0728 \\
\hline 13. Na minha casa, adquiro lâmpadas fluorescentes & 0,3854 \\
\hline 14. Quando compro, preocupo-me em saber se o produto pode ser reciclado depois de utilizado & 0,4179 \\
\hline 15. Faço compras de produtos por impulso & 0,9539 \\
\hline 16. Minha família influencia minhas decisões quando faço compras & 0,3253 \\
\hline 17. Faço a devolução de pilhas e baterias nos locais adequados para seu recebimento & 0,1649 \\
\hline 18. Tenho o cuidado de desligar as luzes quando saio de um cômodo & 0,2243 \\
\hline 19. Quando vou às compras, opto por produtos cuja marca seja conhecida & 0,9079 \\
\hline 110. Em minha casa, tenho o cuidado de separar o lixo produzido por mim & 0,1052 \\
\hline 11 1. Antes de comprar um produto procuro, ativamente, informação sobre seu impacto ambiental & 0,1832 \\
\hline 112. Prefiro desligar os aparelhos a deixá-los em stand-by (modo espera) quando não os utilizo & 0,0177 \\
\hline 113. Gasto muito tempo nas compras, avaliando os produtos & 0,8170 \\
\hline 114. Sou o responsável por fazer as compras para minha casa & 0,6025 \\
\hline 115. Evito produtos com excesso de embalagem & 0,2030 \\
\hline I16. Tenho o cuidado de verificar se há qualquer vazamento de água em minha casa & 0,0933 \\
\hline 117. Evito adquirir produtos que possuam baixo impacto ambiental, pois seus preços são geralmente mais elevados & 0,4875 \\
\hline 118. Quando faço compras, marca é sinônimo de qualidade & 0,6434 \\
\hline I19. Compro produtos com certificação ambiental (Procel, Cerflor, FSC, ISO etc.) & 0,0206 \\
\hline 120. Reutilizo as sacolas plásticas das compras & 0,8622 \\
\hline 121. Prefiro etanol a gasolina, mesmo que não seja a opção mais economicamente viável & 0,7285 \\
\hline 122. Fico confuso quando tenho muitas opções de compra & 0,3854 \\
\hline 123. Prefiro adquirir produtos que contenham conteúdo reciclável e/ou biodegradável & 0,1649 \\
\hline 124. As pessoas que compõem meu agregado familiar se preocupam com o impacto ambiental de nossas compras & 0,4179 \\
\hline 125. Quando faço compras, fico atento a aspectos que envolvam a durabilidade e a vida útil do produto & 0,7285 \\
\hline
\end{tabular}

Fonte: Dados da pesquisa.

Tendência semelhante ocorre quando se observa a afirmação "I19. Compro produtos com certificação ambiental (Procel, Cerflor, FSC, ISO etc.)": os entrevistados que responderam o questionário Tipo I apresentaram respostas com mediana igual a 2 , enquanto as respostas daqueles que responderam o questionário Tipo II possuem mediana igual a 4. Isso permite-nos inferir que as certificações ambientais (Procel, ISO, Cerflor, FSC etc.) pertencem 
a um linguajar técnico da área de compras públicas e que influenciaram a análise das afirmações pelos servidores de forma mais clara no contexto organizacional.

Nesse ponto, cabe trazer uma questão relevante: a legislação brasileira veda a utilização de certificações (ou selos) que não sejam de natureza compulsória, uma vez que tal uso poderia trazer condições de desigualdade na competição entre os licitantes. Inserem-se aqui os selos de qualidade ISO (internacionais) e o FSC. Cabe ressaltar que, quando as respostas às afirmações ligadas ao contexto individual foram respondidas primeiramente (questionário Tipo I), o nível de concordância com as afirmações apresentadas nas questões 12 e 19 no contexto individual foi significativamente menor, em comparação com a concordância dos respondentes nesse mesmo contexto quando ele foi apresentado antes do contexto de compras organizacionais.

A comparação entre as respostas às afirmações sobre o consumo em contexto organizacional foi realizada da mesma forma para os dois grupos. A partir do Teste de Mann-Whitney verificou-se que as questões ligadas ao contexto organizacional não tiveram suas respostas influenciadas por efeitos de ordem, como se pode observar na tabela 3. Possivelmente, essa ausência de influência se deva ao fato de que há um conjunto de critérios que delimitam e direcionam as compras organizacionais públicas, das quais os responsáveis devem ter o conhecimento necessário.

Tabela 3

Análise da consistência das respostas às afirmações da parte III para o contexto de compras organizacionais em função da ordem de exposição aos contextos individual e organizacional, a partir da aplicação do Teste de Mann-Whitney, com nível de decisão $\alpha$ igual a 0,05

\begin{tabular}{|lc|}
\hline Afirmações sobre compras organizacionais & p (bilateral) \\
\hline O1. Utilizo os versos das páginas & 0,0728 \\
O2. Adoto o preço, como critério de seleção das propostas & 0,8622 \\
O3. Em nossa unidade, adquiro lâmpadas fluorescentes & 0,3545 \\
O4. Ao especificar o produto a ser adquirido, preocupo-me em saber se o produto pode ser reciclado depois & 0,7723 \\
de utilizado & 0,6025 \\
O5. Quando possível, prefiro realizar compras por dispensa de licitação & 0,0562 \\
O6. Meu chefe imediato influencia minhas decisões, no momento de especificar os produtos a serem adquiridos \\
O7. Faço a devolução de pilhas e baterias nos locais adequados para seu recebimento & 0,1832 \\
O8. Tenho o cuidado de desligar as luzes quando sou o último a deixar a sala & 0,6434 \\
O9. Quando especifico um produto, no edital de licitação, identifico-o por meio de características de produtos \\
cuja marca seja conhecida & 0,0728 \\
O10. Em minha repartição, tenho o cuidado de separar o lixo produzido por mim & 0,7723 \\
O11. Antes de realizar a aquisição de um produto procuro, ativamente, informação sobre seu impacto ambiental & 0,5628 \\
O12. Prefiro desligar os aparelhos a deixá-los em stand-by (modo espera) quando não os utilizo & 0,2243 \\
O13. Gasto muito tempo nas compras, especificando os produtos & 0,2030 \\
\hline
\end{tabular}




\begin{tabular}{|lc|}
\hline Afirmações sobre compras organizacionais & P (bilateral) \\
\hline O14. Tenho liberdade para decidir qual será a especificação do produto a ser comprado na minha repartição & 0,2472 \\
O15. Incluo, nos editais de licitação, exigências para que os produtos sejam fornecidos sem excesso de & 0,9079 \\
embalagem & 0,6854 \\
O16. Tenho o cuidado de comunicar ao setor responsável se há qualquer vazamento de água em minha \\
repartição \\
$\begin{array}{l}\text { O17. Evito utilizar especificações (Catmat) cujos produtos sejam de baixo impacto ambiental, pois seus preços } \\
\text { são geralmente mais elevados }\end{array}$ & 0,3545 \\
O18. Quando adquiro um produto de marca conhecida, entendo que foi adquirido um produto de qualidade & 0,5628 \\
O19. Adquiro, em minha unidade, produtos cuja especificação exija certificação ambiental (Procel, Cerflor, & 0,1649 \\
FSC, ISO etc.) & 0,7723 \\
O20. Em minha unidade, procuro reaproveitar embalagens e envelopes para o envio de correspondências \\
ou transporte de mercadorias \\
O21. Ao abastecer o veículo de minha repartição, entendo que se deve preferir etanol a gasolina, mesmo que \\
não seja a opção mais economicamente viável \\
O22. Fico confuso quando tenho muitas opções de compra \\
O23. Especifico produtos, no processo de aquisição, que contenham conteúdo reciclável e/ou biodegradável \\
O24. As pessoas que compõem minha equipe se preocupam com o impacto ambiental de nossas aquisições \\
O25. Incluo, na especificação do produto a ser adquirido, critérios de seleção que avaliem sua durabilidade \\
e vida útil & 0,3253 \\
\hline
\end{tabular}

Fonte: Dados da pesquisa.

Em conjunto, os dados das tabelas 2 e 3 mostram que, independente da ordem de exposição aos contextos de consumo, as respostas dadas pelos participantes a um mesmo contexto tenderam a ser semelhantes.

\subsection{Análise dos níveis de concordância nos contextos de consumo individual e organizacional}

Ao se verificar que não houve diferenças nas respostas derivadas da ordem de exposição para 23 das 25 questões no contexto de consumo individual e para as 25 no contexto de compras organizacionais, é possível agrupar os dados dos diferentes participantes de forma a se analisar os níveis de concordância dos participantes com as respectivas afirmativas nos dois contextos. A figura 2 apresenta a mediana da concordância com as afirmações de consumo individual (parte superior) e organizacional (parte inferior). No contexto de consumo individual, quatro questões obtiveram mediana 5 (concordo totalmente): questão 2 (adquiro produtos de menor preço); questão 8 (tenho o cuidado de desligar a luz quando saio de um cômodo); questão 16 (tenho cuidado de verificar se há qualquer vazamento de água em minha casa); e, questão 20 (reutilizo as sacolas plásticas das compras). 
Figura 2

Mediana e intervalos interquartis para as frequências e concordâncias a cada uma das afirmações no contexto individual (gráfico superior) e organizacional (gráfico inferior) (As hastes com círculos nas extremidades representam o intervalo interquartil. O quadrado, por sua vez, indica a mediana.)
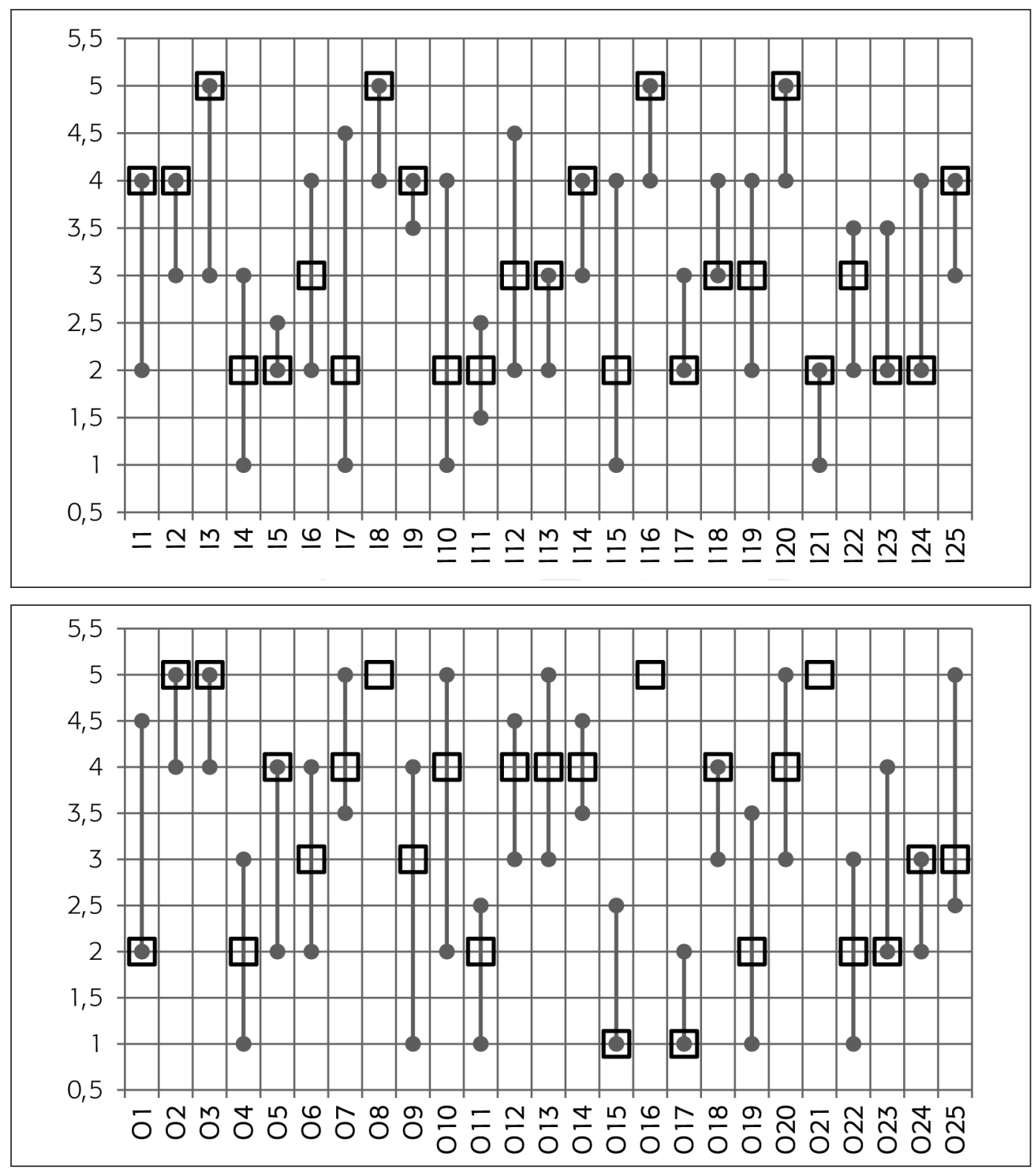

Fonte: Dados da pesquisa. 
Nas questões referentes ao contexto organizacional, para cinco questões a mediana da concordância foi de 5: questão 2 (adoto o preço como critério de seleção das propostas); questão 3 (em nossa unidade adquiro lâmpadas fluorescentes); questão 8 (tenho o cuidado de desligar as luzes quando sou o último a deixar a sala); questão 16 (tenho o cuidado de comunicar ao setor responsável se há qualquer vazamento de água em minha repartição); questão 21 (ao abastecer o veículo em minha repartição, entendo que se deve preferir etanol a gasolina, mesmo que não seja a opção mais economicamente viável). Observa-se que em três casos (questões 3, 8 e 16) as questões correlatas no contexto organizacional e individual tiveram concordância total. Além disso, a questão 20 no contexto de consumo organizacional também teve alto nível de concordância (mediana $=4$ ). Apenas a questão 21 não teve níveis de concordância semelhantes nos dois contextos, conforme será abordado na próxima seção.

No contexto organizacional, duas questões, 15 (incluo, nos editais de licitação, exigências para que os produtos sejam fornecidos sem excesso de embalagem) e 17 (evito utilizar especificações (Catmat) cujos produtos sejam de baixo impacto ambiental, pois seus preços são geralmente mais elevados), tiveram nível mediano de frequência nula.

Analisando-se especificamente as questões que apontam diretamente para questões ambientais, todas tiveram respostas semelhantes nos dois contextos. Destas, as questões I3/O3 (aquisição de lâmpadas fluorescentes) e I8/O8 (desligar luzes ao sair) apresentaram medianas altas, e a questão I17/O17 (evito produtos de baixo impacto ambiental) teve mediana baixa. Nos três casos, as respostas indicam alta frequência de comportamento pró-ambiental. Por outro lado, as questões I10/O10 (separação de lixo), I15/O15 (evita produtos com excesso de embalagem) e I23/O23 (preferência por produtos reciclados ou biodegradáveis) tiveram medianas entre 1 e 2 , indicando que esses são comportamentos com frequências extremamente baixas nos dois contextos.

\subsection{Diferenças entre consumo individual e organizacional}

O passo seguinte, na presente investigação, foi identificar se o comportamento do gestor público era influenciado de forma distinta pelas variáveis selecionadas. Para tal investigação, aplicou-se o Teste de Wilcoxon, com nível de decisão $\beta$ igual a 0,05, obtendo-se o resultado explicitado na tabela 4. Nesse caso, a hipótese considerada é a de que o contexto no qual a afirmação é feita é irrelevante para o comportamento do indivíduo. Assim, será comparada a afirmação I(n) (contexto individual) com a afirmação $\mathrm{O}(\mathrm{n}$ ) (contexto organizacional), em que $\mathrm{n}=1,25$.

Antes de prosseguir com a análise dos resultados, deve-se mencionar que, uma vez que as afirmações I12 e I19 apresentaram efeito de ordem, as comparações, nesses casos, foram feitas para os dois tipos de questionários (Tipos I e II) e, por isso, possuem dois resultados possíveis. 


\section{Tabela 4}

Análise das respostas entre os contextos individual e organizacional sobre o comportamento do consumidor, a partir da aplicação do Teste de Wilcoxon, com nível de decisão $\beta$ igual a 0,05 (As questões 12 e 19 apresentam dois dados em virtude das diferenças encontradas nas respostas ao contexto individual com as diferentes ordens de exposição.)

\begin{tabular}{|cccccc|}
\hline Comparação & $\mathrm{p}$ (bilateral) & Comparação & $\mathrm{p}$ (bilateral) & Comparação & $\mathrm{p}$ (bilateral) \\
\hline 11 vs. 01 & 0,3270 & 110 vs. 010 & 0,1235 & 118 vs. 018 & 0,0747 \\
12 vs. 02 & 0,0051 & 111 vs. 011 & 0,8590 & 119 vs. 019 & 0,1088 \\
& & & & 0,5294 \\
13 vs. 03 & 0,0679 & 112 vs. 012 & 0,3452 & 120 vs. 020 & 0,2719 \\
14 vs. 04 & 0,8886 & 113 vs. 013 & 0,0499 & 121 vs. 021 & 0,0007 \\
15 vs. 05 & 0,0047 & 114 vs. 014 & 0,6002 & 122 vs. 022 & 0,0382 \\
16 vs. 06 & 0,4498 & 115 vs. 015 & 0,4772 & 123 vs. 023 & 0,8658 \\
17 vs. 07 & 0,0284 & 116 vs. 016 & 0,0277 & 124 vs. 024 & 0,5940 \\
18 vs. 08 & 0,1159 & 117 vs. 017 & 0,1424 & 125 vs. 025 & 0,7532 \\
19 vs. 09 & 0,0284 & & & & \\
\hline
\end{tabular}

Fonte: Dados da pesquisa.

Dos resultados ilustrados pela tabela 4, pode-se concluir que oito situações (fatores críticos) apresentadas aos entrevistados (afirmações 2, 5, 7, 9, 13, 16, 21 e 22) evidenciaram que o contexto no qual a compra está inserida é relevante para a análise, sendo estas marcadas em negrito. Desse ponto em diante, esses oito fatores serão pormenorizadamente analisados, sendo divididos nas três seções que se seguem.

\subsubsection{Legislação vigente}

Como já citado previamente, o preço do produto e sua marca se constituem em fatores críticos no processo decisório de compra (Sener e Hazer, 2008; Wheale e Hinton, 2007). Essa expectativa foi confirmada nesta investigação. Entretanto, deve-se notar que tais resultados se mostraram dependentes em relação ao contexto de compra no qual o indivíduo (gestor público) está envolvido. Vê-se, por exemplo, do gráfico 1, que o fator preço apresentou maior importância no contexto organizacional. Pode-se inferir que tal comportamento está intrinsecamente ligado à exigência trazida pela Lei no 8.666/1993 em seu artigo 45, §1ํㅡ, qual seja: "constituem tipos de licitação (...): a de menor preço (...); a de melhor técnica; a de técnica e preço; a de maior lance ou oferta (...)". Além disso, o art. 46 do mesmo dispositivo estabelece 
que "os tipos de licitação melhor técnica ou técnica e preço serão utilizados exclusivamente para serviços de natureza predominantemente intelectual". Ou seja, isso demonstra que a maior parte das licitações (e é o que ocorre na modalidade pregão eletrônico, a mais utilizada pelos entrevistados) se processa com o julgamento das propostas obedecendo como critério o menor preço.

$$
\text { Gráfico } 1
$$

Comportamento do consumidor em face das afirmações 12 e 02, que avaliam a influência do preço na decisão de compra. As respostas dos entrevistados são as seguintes: 1 (nunca); 2 (minoria das vezes); 3

(metade das vezes); 4 (maioria das vezes) e 5 (sempre)

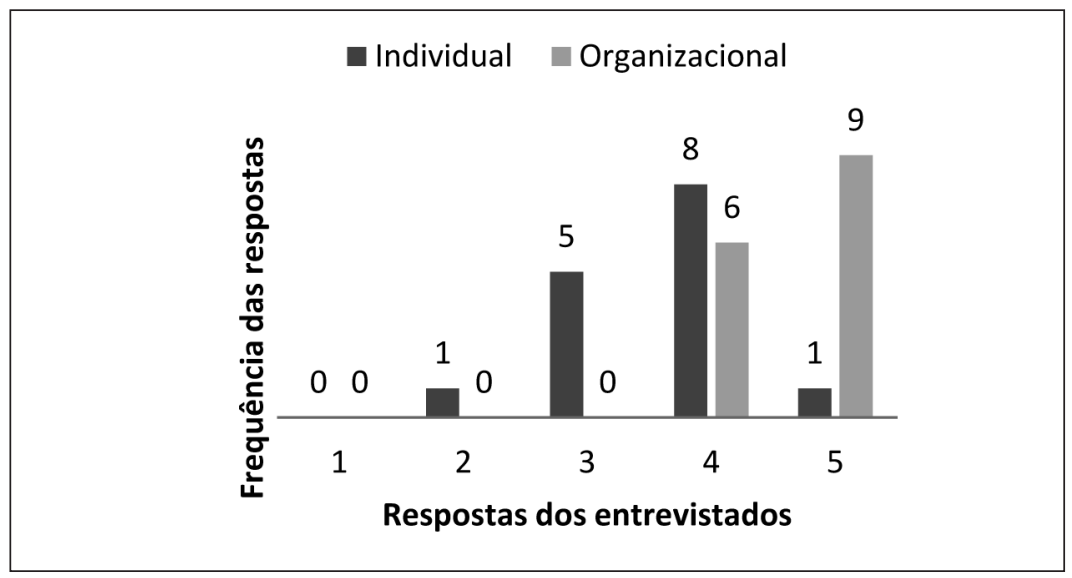

Fonte: Dados da pesquisa.

Fique claro que a exigência do menor preço não impede o gestor público de buscar meios de especificar, com clareza, os bens e/ou serviços a serem contratados e de exigir determinados requisitos mínimos de qualidade, desde que sejam permitidos por lei. Entretanto, a legislação sobre o tema (Lei no $8.666 / 93$, art. 15, $7^{\circ}$, I) traz a vedação à indicação de marcas, que poderiam se traduzir em bons indicadores de qualidade, mas que, por outro lado, dariam margem ao direcionamento das licitações.

Note que, do gráfico 2, a marca do produto está presente como fator relevante para a decisão de compra nos dois contextos. Entretanto, tal fator perde força quando se avalia o contexto organizacional, justamente pela vedação já tratada. Esperava-se, no entanto, que a marca tivesse pequena influência no contexto organizacional.

A justificativa para tal resultado pode ser extraída da prática das licitações, onde se verifica que, mesmo sem indicar a marca, é possível especificar em demasia o produto, indicando características que se encontram em produtos de determinadas marcas. 


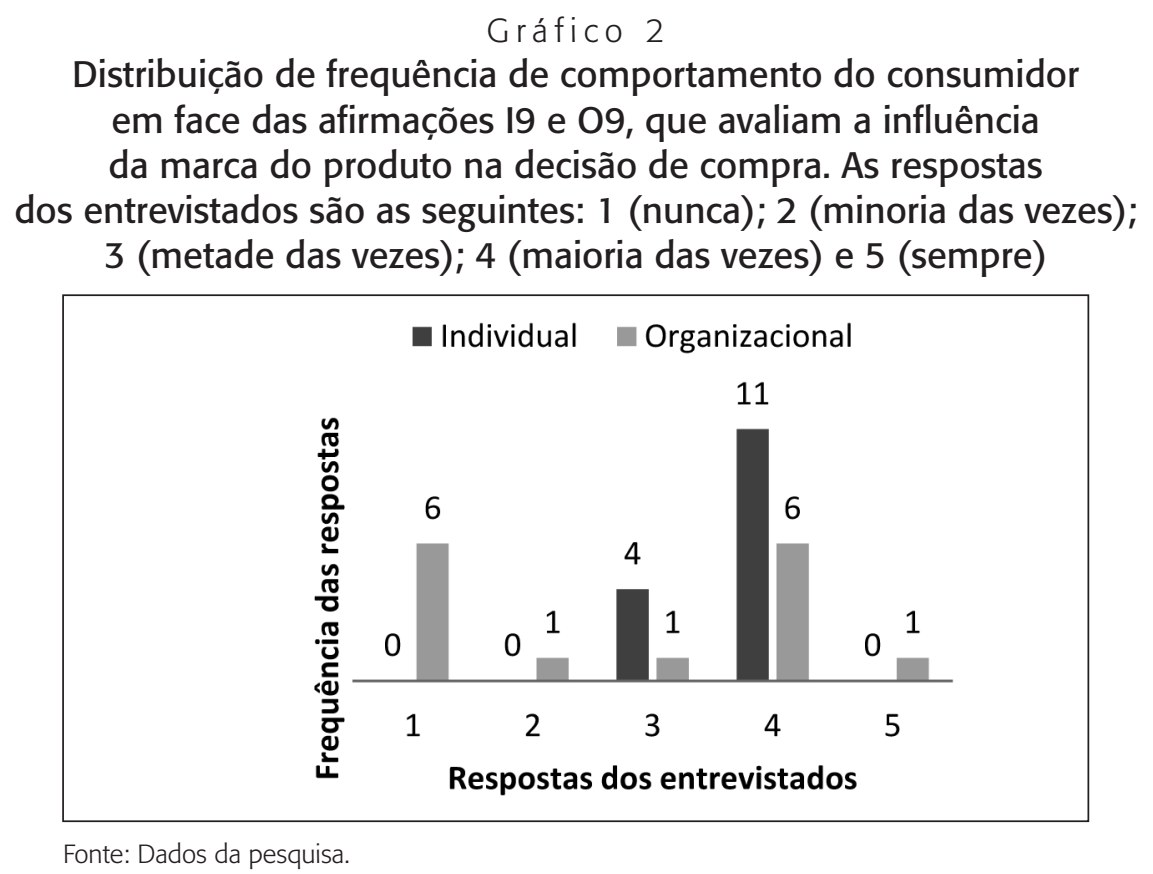

Para confirmar esse entendimento, observe a seguinte especificação para uma caneta esferográfica contida no Catálogo de Material (Catmat) (um sistema governamental que deve ser utilizado como referência pelos gestores públicos na especificação de bens a serem adquiridos): “CANETA ESFEROGRÁFICA, MATERIAL PLÁSTICO, QUANTIDADE CARGAS 1, MATERIAL PONTA AÇO INOXIDÁVEL COM ESFERA DE TUNGSTÊNIO, TIPO ESCRITA MÉDIA, COR TINTA AZUL, CARACTERÍSTICAS ADICIONAIS CORPO SEXTAVADO, TRANSPARENTE E ORIFÍCIO LATERAL".

Nesse caso, não é necessário sequer dizer qual a marca desejada. Por isso, mesmo que seja proibido o julgamento das propostas dos fornecedores com base na marca do produto, tal fator pode, sim, influenciar a decisão de compra no contexto organizacional.

\subsubsection{Ações de política ambiental da instituição}

Na sequência, pode-se observar a relevância das ações de política ambiental da própria instituição sobre o comportamento de seus servidores. Do gráfico 3, pode-se aferir os hábitos de descarte adequado de pilhas e baterias de tais indivíduos (afirmações I7 e O7) e verificar que tal hábito é mais frequente no contexto organizacional. Mesmo que não tenham mostrado significativa discrepância em relação ao contexto de compra, as afirmações 110 e O10 (que também refletem hábitos quanto ao descarte), quando comparadas, apresentam a mesma tendência verificada no gráfico 3 . 
Tal preocupação com os hábitos de descarte, demonstrada pelos entrevistados, devese às recentes iniciativas da administração do IBGE no intuito de melhorar os hábitos de consumo de seus servidores. Tal iniciativa teve como ações principais: o incentivo à redução no consumo de alguns bens e serviços; a aquisição de lixeiras para coleta seletiva e recipientes específicos para deposição de pilhas e baterias; a produção e disseminação de cartilha incentivando novos hábitos nos servidores. Tais ações foram reunidas no intitulado Programa de Melhoria da Qualidade do Gasto (PMQGasto), de iniciativa da DiretoriaExecutiva.

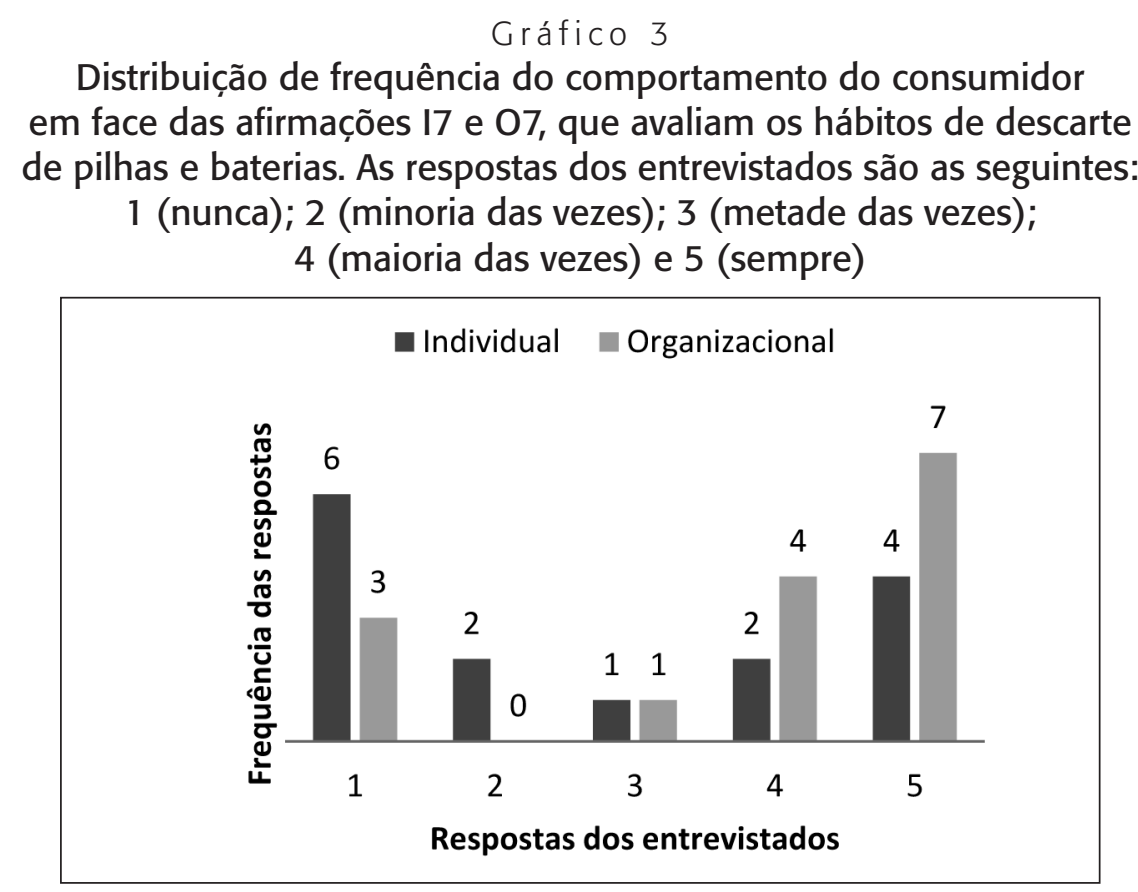

Fonte: Dados da pesquisa.

Outra ação tomada pela instituição que mostrou significativa importância na mudança de hábito nos servidores da instituição, aqui evidente pelo comportamento dos servidores ligados à área de compras, refere-se à orientação da Coordenação de Recursos Materiais, emanada por meio do Memorando-Circular no 01/2011, às unidades estaduais do IBGE e à administração central, para que utilizem, obrigatoriamente, o combustível álcool em todos os veículos oficiais que possuam a tecnologia flex fuel, mesmo nas hipóteses em que o preço do álcool não seja economicamente vantajoso em relação à gasolina (maior que 70\%).

Tal decisão coincide com o texto da Lei no 9.660/1998, a qual exigiu que a renovação da frota fosse feita com a aquisição de veículos movidos a combustíveis renováveis. Não faria sentido adquirir veículos movidos a combustíveis renováveis e utilizar a opção de combustível não renovável. 
Nota-se, a partir do gráfico 4, que, no contexto organizacional, a preferência pelo combustível álcool é expressiva. Essa preferência, em virtude da legislação, acaba por confrontar as respostas à afirmação $\mathrm{O} 2$, em que nas compras organizacionais a maior frequência indicou considerar o preço nas aquisições (referentes a licitações e tomadas de preço). Já no contexto de compras individuais (ou domésticas), vê-se que o indivíduo continua a optar meramente pelo critério do menor preço, consonante com as respostas à afirmação I2, visto não haver uma regulamentação que determine ou reforce essa prática em seu dia a dia, desconsiderando os ganhos ambientais do consumo alternativo.

\section{Gráfico 4}

Comportamento do consumidor em face das afirmações 121 e 021 , que avaliam a decisão de compra de combustíveis (gasolina ou etanol). As respostas dos entrevistados são as seguintes: 1 (nunca); 2 (minoria das vezes); 3 (metade das vezes); 4 (maioria das vezes) e 5 (sempre)

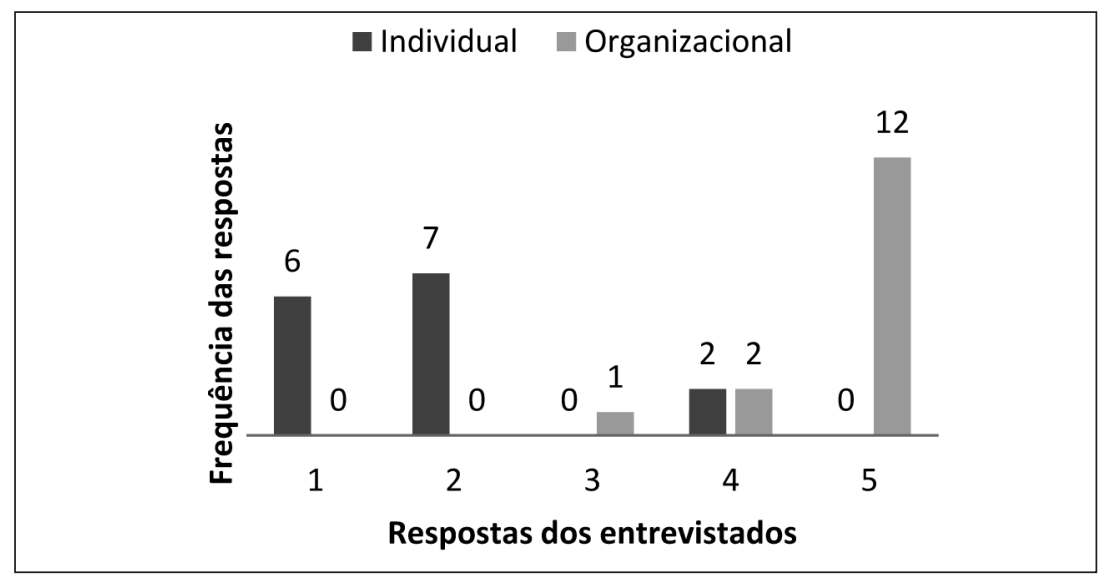

Fonte: Dados da pesquisa.

Aqui, outra questão pode ser levantada: como, nas compras organizacionais, os recursos financeiros não saem diretamente do "bolso" de quem os adquire, sendo custeados pelo erário público, parece ser mais fácil cumprir aos requisitos de ordem ambiental. Essa compreensão pode ser ratificada por outro questionamento da presente investigação. Apesar de não apresentar diferenças significativas entre os contextos de compra, cabe avaliar o resultado obtido pela comparação das respostas dadas em face das afirmações I17 e 017, trazidas no gráfico 5, que tratam justamente desse trade-off entre preço e impacto ambiental de bens e serviços.

Do gráfico 5 observa-se que, no contexto organizacional, os gestores não evitam a especificação de produtos que sejam de baixo impacto ambiental, mesmo cientes de que seus preços de mercado são usualmente superiores. Isso não ocorre, com a mesma intensidade, no contexto de compras domésticas, evidenciando que o fator que realmente interfere na decisão de compra não é o preço, mas, sim, a disponibilidade de recursos financeiros pelo comprador. 
Gráfico 5

Comportamento do consumidor em face das afirmações 117 e 017, que avaliam a escolha entre o menor preço e a qualidade ambiental de bens e serviços a serem adquiridos. As respostas dos entrevistados são as seguintes: 1 (nunca); 2 (minoria das vezes); 3 (metade das vezes); 4 (maioria das vezes) e 5 (sempre)

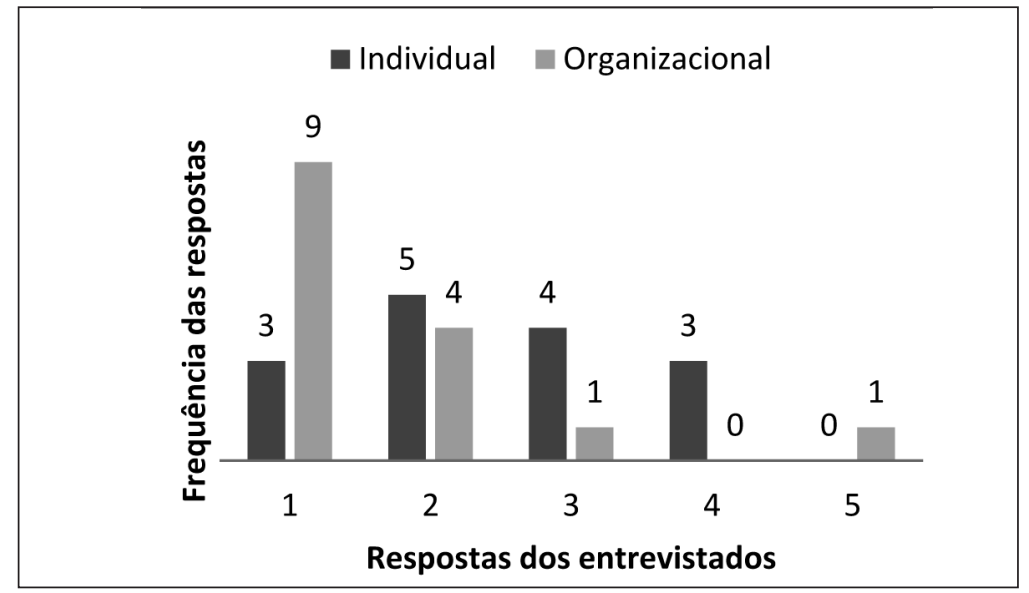

Fonte: Dados da pesquisa.

\subsubsection{Tempo envolvido no processo decisório}

Por fim, serão avaliadas duas comparações que se referem, na verdade, a uma mesma variável, qual seja: a disponibilidade de tempo para tomar a decisão referente a dada compra. Por apresentarem análises semelhantes, trataremos aqui da comparação entre as afirmações I13 e 013, que questionou com qual frequência os entrevistados gastavam muito tempo nas compras que efetuavam, cujo resultado encontra-se exposto no gráfico 6.

Com base no gráfico 6, evidencia-se que, no contexto individual, os entrevistados gastam pouco tempo avaliando sua decisão de compra, na maioria das vezes. Já no contexto organizacional, observa-se comportamento distinto. De modo inequívoco, não se afirma aqui que tal discrepância no comportamento, a depender dos contextos de compra envolvidos, seja capaz de estabelecer um dualismo entre consumo individual e organizacional. O que se assevera, tão simplesmente, é que os fatores críticos que influenciam tais processos decisórios variam, de acordo com o contexto dado.

O entendimento aqui firmado coaduna-se com o de Wilson (2000). Esse autor argumenta que, quando se considera que as compras realizadas por consumidores individuais aparentam ser apressadas ou, até mesmo, espontâneas, na verdade ignora-se a riqueza do rápido processamento de informações, consciente ou não. Por outro lado, analisa que a aparente lentidão de alguns processos de aquisição em organizações pode ser explicada em termos da necessidade de conformar o processo às expectativas, culturais e burocráticas, da organização. 


\section{Gráfico 6}

Comportamento do consumidor em face das afirmações 113 e 013, que avaliam o tempo gasto durante o processo de compra. As respostas dos entrevistados são as seguintes: 1 (nunca); 2 (minoria das vezes); 3 (metade das vezes); 4 (maioria das vezes) e 5 (sempre)

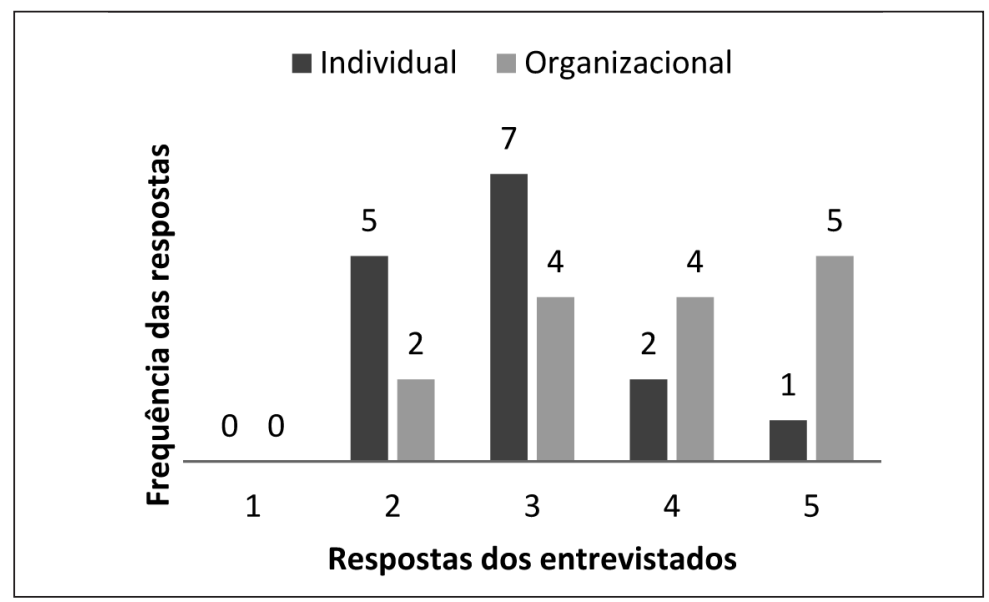

Fonte: Dados da pesquisa.

De fato, pode-se afirmar que os dois contextos envolvem consequências específicas para o comportamento do consumidor ou para o grupo. No consumo individual, consequências imediatas afetam o comportamento do comprador. Além disso, um conjunto maior de informações acerca do produto está disponível e pode ser considerado durante a procura por produtos. Oliveira-Castro e Foxall (2005) enfatizam que o tempo gasto na procura por produtos é função da quantidade de alternativas disponíveis e do preço médio dos produtos e, na maioria das vezes, o consumo individual lida com produtos de preços mais baixos. Já o consumo organizacional envolve contexto e consequências diferentes. O processo de tramitação de licitações imputa um atraso à obtenção e uso dos produtos, menor acesso a informações (como ausência de informações sobre marcas, por exemplo) e, principalmente, envolve alta frequência de compras de produtos com preços mais altos ou que envolvem maior quantidade de gastos por compras.

\section{Conclusão}

Este trabalho objetivou analisar o comportamento em situações de consumo individual e organizacional de pessoas que são responsáveis por compras organizacionais de uma instituição, com relação a diferentes aspectos envolvidos no consumo (procura, compra, uso e descarte), focando aspectos relacionados com a sustentabilidade. De certa forma, procurou-se saber se haveria semelhança ou diferença entre os padrões nos dois contextos. Os padrões de respostas para a maioria das afirmações apresentadas aos participantes não diferiram significativamente. Esse dado é consistente, visto que avaliaram-se as respostas dos mesmos indivíduos diante 
das afirmativas nos dois contextos. Apesar disso, situações semelhantes tiveram respostas diferentes quando o consumo era individual e quando era organizacional. Essas diferenças encontraram-se prioritariamente em questões que envolvem preço e tempo gasto nas especificações dos produtos a serem adquiridos. De forma geral, o preço foi mais determinante no contexto individual, e gasto no tempo com especificações foi mais frequente no contexto organizacional, indicando efeitos diferenciais de consequências utilitárias no primeiro caso e de fatores regulatórios presentes no cenário no segundo.

Chamam atenção as semelhanças entre as respostas a questões que envolvem questões ambientais nos dois contextos. Alguns padrões pró-ambientais se mostram bem estabelecidos, como utilização dos versos das páginas, desligar as luzes e aparelhos (em vez de deixá-los em stand-by). Esses comportamentos têm consequência comum relacionada com a diminuição do gasto, uma consequência utilitária. No contexto organizacional específico da presente investigação, como já dito, foi implantada em 2012 uma campanha de qualidade do gasto, que pode ter sido efetiva no estabelecimento desses comportamentos. Porém, os efeitos desses comportamentos são ainda restritos.

Por outro lado, comportamentos que têm consequências a longo prazo e que apresentam efeitos para um maior número de pessoas, como separar lixo, evitar produtos com excesso de embalagem e preferência por produtos reciclados, tiveram baixa frequência nos dois contextos. Isso indica que há necessidade de desenvolvimento de programas mais efetivos que visem aumentar o valor das consequências ambientais no longo prazo, sinalizando os possíveis ganhos sociais de práticas como essas. A principal prática tem envolvido campanhas com textos pró-ambientais e feedback. Quanto a isto, Foxall e colaboradores (2006) ressaltam que há fortes ligações entre comportamentos de conservação e suas consequências, e os dados mostram que incentivos aliados a feedback têm efeitos mais imediatos e duradouros. Além disso, os incentivos isoladamente têm efeitos maiores do que ofeedback isolado. O uso de consequências mais imediatas pode, assim, aumentar a frequência dos comportamentos pró-ambientais, permitindo o contato com as consequências de longo prazo desses comportamentos.

Por fim, a presente pesquisa também sinaliza para o fato de que o maior desafio para a implementação da política pública de compras sustentáveis reside no tabuleiro da gestão e não no âmbito jurídico. Viu-se como as iniciativas institucionais (aqui trazendo-se o IBGE como parâmetro) têm o condão de superar eventuais restrições (necessárias) impostas pela legislação, estimulando comportamentos pró-ambientais, o que referenda uma desejada mudança de paradigma rumo à sustentabilidade. Pesquisas futuras podem comparar cenários organizacionais diversos e utilizar-se de outras medidas comportamentais que permitam correlacionar a correspondência entre o dizer (resposta aos questionários) e o fazer (efetiva emissão de comportamentos sustentáveis) nos diferentes contextos, e o papel de consequências utilitárias e informativas.

\section{Referências}

ARRAIS, Inês P. O comportamento do consumidor face a questões ambientais. Dissertação (mestrado) — Universidade de Aveiro, Aveiro, 2009. 
BATISTA, Marco Antônio C.; MALDONADO, José Manuel S. V. O papel do comprador no processo de compras em instituições públicas de ciência e tecnologia em saúde (C\&T/S). Rev. Adm. Pública, v. 42, n. 4, p. 681-699, 2008.

BIDERMAN, Rachel et al. Guia de compras públicas sustentáveis: uso do poder de compra do governo para a promoção do desenvolvimento sustentável. Rio de Janeiro: Editora FGV, 2006. v. 1.

BRODHAG, Christian. A differentiated approach for sustainable consumption and production policies. Natural Resources Forum, v. 34, n. 1, p. 63-70, 2010.

DOBSON, Andrew. Environmental citizenship: towards sustainable development. Sustainable Development, v. 15, n. 5, p. 276-285, 2007.

FOXALL, Gordon. R. Consumer psychology in behavioral perspective. Londres; Nova York: Routledge, 1990.

FOXALL, Gordon. R. Theoretical and conceptual advances in consumer behavior analysis. Journal of Organizational Behavior Management, v. 30, n. 1, p. 92-109, 2010.

FOXALL, Gordon. R. The substitutability of brands. Managerial and Decisions Economics, v. 20, n. 5, p. 241-257, 1999.

FOXALL, Gordon. R. Understanding consumer choice. Palgrave McMillian: Hampshire, 2005.

FOXALL, Gordon R. et al. Consumer behavior analysis and social marketing: the case of environmental conservation. Behavior and Social Issues, v. 15, n. 1, p. 101-124, 2006.

FOXALL, Gordon. R. et al. Consumer behaviour analysis and the behavioural perspective model. Management Online Review (More), 2011. Disponível em: < http://dro.dur.ac.uk/7962/1/7962. pdf?DDD2+dbr4wd >. Acesso em: 10 jan. 2013.

GAO, Tao; SIRGY, Joseph M.; BIRD, Monroe M. Reducing buyer decision-making uncertainty in organizational purchasing: can supplier trust, commitment, and dependence help? Journal of Business Research, v. 58, n. 4, p. 397-405, 2005.

GILG, Andrew; BARR, Stewart; FORD, Nicholas. Green consumption or sustainable lifestyles? Identifying the sustainable consumer. Futures, v. 37, n. 6, p. 481-504, 2005.

GREEN, Ken et al. Greening organizations: purchasing, consumption and innovation. Organization \& Environment, v. 13, n. 2, p. 206-225, 2000.

JAAKKOLA, Elina. Purchase decision-making within professional consumer services: organizational or consumer buying behaviour? Marketing Theory, v. 7, n. 1, p. 93-108, 2007.

LANE, Ben; POTTER, Stephen. The adoption of cleaner vehicles in the UK: exploring the consumer attitude-action gap. Journal of Cleaner Production, v. 15, n. 11-12, p. 1085-1092, 2007.

MCDONALD, Seonaidh; OATES, Caroline J. Sustainability: consumer perceptions and marketing strategies. Business Strategy and the Environment, v. 15, n. 3, p. 157-170, 2005.

MOISANDER, Johanna. Motivational complexity of green consumerism. International Journal of Consumer Studies, v. 31, n. 4, p. 404-409, 2007. 
NTAYI, Joseph M. et al. Moral schemas and corruption in Uganda public procurement. Journal of Business Ethics, v. 112, n. 3, p. 417-436, fev. 2013.

OECD. Greener public purchasing: issues and practical solutions. Paris: Oecd Publications, 2000.

OLIVEIRA-CASTRO, Jorge M.; FOXALL, Gordon R. Análise do comportamento do consumidor. In: RODRIGUES, Josele A.; RIBEIRO, Michela R. (Org.). Análise do comportamento: pesquisa, teoria e aplicação. Porto Alegre: Artmed, 2005. p. 283-304.

PELSMACKER, Patrick et al. Do consumers care about ethics? Willingness to pay for fair-trade coffee. The Journal of Consumer Affairs, v. 39, n. 2, p. 363-385, 2005.

POHL, Roberta H. B. F. et al. Efeitos do nível de benefício utilitário sobre a duração do comportamento de procura por produtos. Revista Psicologia, Organizações e Trabalho, v. 6, n. 1, p. 233-264, 2006.

SAMMER, Katharina; WÜSTENHAGEN, Rolf. The influence of eco-labelling on consumer behavior - results of a discrete choice analysis for washing machines. Business Strategy and the Environment, v. 15, n. 3, p. 185-199, 2006.

SENER, Arzu; HAZER, Ora. Values and sustainable consumption behaviour of women: a Turkish sample. Sustainable Development, v. 16, n. 5, p. 291-300, 2008.

SILVA, Renato C.; BARKI, Teresa V. P. Compras públicas compartilhadas: a prática das licitações sustentáveis. Revista do Serviço Público, v. 63, n. 2, p. 157-175, 2012.

SOLOMON, Michael R. Comportamento do consumidor: comprando, possuindo e sendo. 5. ed. Porto Alegre: Bookman, 2002.

UNITED NATIONS. Report of the World Summit on Sustainable Development - Johannesburg, South Africa, 26 August-4 September, 2002.

WHEALE, Peter; HINTON, David. Ethical consumers in search of markets. Business Strategy and the Environment, v. 16, n. 4, p. 302-315, 2007.

WILSON, Dominic F. Why divide consumer and organizational buyer behaviour? European Journal of Marketing, v. 34, n. 7, p. 780-796, 2000.

YOUNG, William et al. Sustainable consumption: green consumer behaviour when purchasing products. Sustainable Development, v. 18, n. 1, p. 20-31, 2010.

Hugo Leonnardo Gomides do Couto é doutorando em ciências ambientais na Universidade Federal de Goiás (UFG). E-mail: hlcouto@gmail.com.

Cristiano Coelho é professor adjunto da Pontifícia Universidade Católica de Goiás (PUCGoiás). E-mail: cristicoelho@gmail.com. 
